\title{
COLORADOSCHOOLOFMINES
}

EARTH•ENERGY•ENVIRONMENT

DiVISION OF ECONOMICS AND BUSINESS

WORKING PAPER SERIES

\section{Subglobal Carbon Policy and the Competitive Selection of Heterogeneous Firms}

Edward J. Balistreri

Thomas F. Rutherford

Working Paper 2012-01

http://econbus . mines . edu/working-papers/wp201201.pdf

Colorado School of Mines

Division of Economics and Business

1500 Illinois Street

Golden, CO 80401

June 2012

(c) 2012 by the listed authors. All rights reserved. 
Colorado School of Mines

Division of Economics and Business

Working Paper No. 2012-01

June 2012

Title:

Subglobal Carbon Policy

and the Competitive Selection of Heterogeneous Firms*

Author(s):

Edward J. Balistreri

Division of Economics and Business

Colorado School of Mines

Golden, CO 80401-1887

ebalistr@mines.edu

Thomas F. Rutherford

Optimization Theme

Wisconsin Institute for Discovery

University of Wisconsin

Madison, WI 53715

rutherford@aae.wisc.edu

\begin{abstract}
We analyze subglobal action to mitigate climate change with a consideration of recent advances in the theory of international trade. Subglobal action impacts emissions in unconstrained countries (carbon leakage) through international trade channels. Consequently, estimates of the efficacy of subglobal action, tariffs on embodied carbon, and the distribution of policy costs will be sensitive to the assumed structure of international trade. While most climate-policy models rely on an Armington (1969) structure of international trade, recent empirical evidence supports a new theory suggested by Melitz (2003). We find significant quantitative and qualitative differences when we consider the Melitz trade structure. These differences are important as an alternative, and arguably more plausible, representation of how trade and border adjustments interact with climate policy.
\end{abstract}

JEL codes: F12, F18, Q54, Q56.

* This study was conducted as part of an Energy Modeling Forum (EMF) model comparison project. As a subgroup of EMF 24, the project included 12 modeling groups studying trade and competitiveness aspects of climate change policy, with a particular focus on border carbon adjustments. We are grateful for comments and suggestions offered by participants of the model comparison meetings held in Zürich and Oslo in 2011. We also acknowledge the support of ETH Zürich, the Colorado School of Mines, and the National Center for Atmospheric Research (NCAR) Integrated Assessment Modeling (IAM) group. Any errors or omissions remain the responsibility of the authors. 


\section{Introduction}

Over the past decade a consideration of the inherent heterogeneity of firms has lead to enormous advances in the theory of international trade. Melitz (2003) formalizes a relatively clear heterogeneous-firms theory of trade, which forms the foundation for many of these advances. The Melitz theory is one of monopolistic competition involving the competitive selection, into each bilateral market, of firms that differ in their productivity. In the context of an empirical analysis of subglobal climate policy the heterogeneous firms structure indicates changes in firm selection with important implications for competitiveness. This study extends and complements the trade-policy application in Balistreri et al. (2011) by examining subglobal carbon policy. Relative to a more traditional trade structure, we find significant quantitative and qualitative differences under the Melitz formulation of trade. These differences are important as an alternative, and arguably more realistic, representation of how trade and border adjustments interact with subglobal climate policy.

We develop a multiregion trade model similar to many that have appeared in the climatepolicy literature with the exception that we assume production of the energy intensive manufacturing (EIT) sector follows the Melitz theory. In order to contrast this treatment with the standard assumptions, we compare results with an Armington (1969) structure model calibrated to a common benchmark dataset. The models are calibrated to a global equilibrium using GTAP 7 data, following the GTAP in GAMS methods and energy demand structure [Böhringer and Rutherford (2011)]. The heterogeneous-firm specific parameters are taken from the structural estimates in Balistreri et al. (2011). The specific policy instruments that we consider include emissions restrictions by subglobal coalitions and carbon-based border adjustments applied to trade in energy intensive goods.

Balistreri et al. (2011) offer an extended review of the empirical literature that supports a heterogeneous-firms international trade structure. Here we highlight some of the key findings 
from that literature. Central to these findings is the coexistence of very different firms within the same industry. Authors looking at firm-level data [e.g., Bartelsman and Doms (2000), Bernard and Jensen (1999), and Roberts and Tybout (1997)] show robust and persistent differences in productivities, size, and export behavior. Furthermore, Aw et al. (2001) and Trefler (2004) provide evidence that policy can induce productivity changes likely due to within industry competitive selection of more or less productive firms. Bustos (2011) looks specifically at the impact of trade on technology adoption. Of relevance to climate policy, Batrakova and Davies (2010) provide evidence that firm-level export behavior is linked to heterogeneity in energy intensities, and Martin (2012) uses Bustos' model to examine the impact of trade on greenhouse gas emissions by Indian manufacturing firms. The clear conclusion from this literature is that firm heterogeneity is an important feature of industrial organization and trade.

Theories consistent with the empirical evidence on firm heterogeneity imply large competitive effects; because, in addition to traditional trade-induced interindustry reallocations, there are trade-induced intra-industry reallocations. A region that places restrictions on emissions from energy intensive production raises production costs and therefore raises the threshold for export engagement. This reallocates resources within the industry toward less productive plants. In contrast, non-regulated regions experience a lowering of the export threshold (as regulated-region prices increase) inducing a reallocation of resources, in the non-regulated regions, toward more productive plants. Productivity falls in regulated regions and rises in unregulated regions. The competitive effects of subglobal policy are, thus, potentially magnified under a heterogeneous firms structure. Our goal here is to quantify these effects. Consistent with our expectations, the heterogeneous-firms structure indicates larger competitive effects, larger leakage rates (but more effective border adjustments), and substantially different conclusions about policy burden shifting. 


\section{Model Description}

In this section we offer a description of the empirical simulation model. Our model is similar to other computable general equilibrium models established in the literature on global trade and climate policy. In particular, our model is directly developed from the canonical model presented by Böhringer and Rutherford (2011). The model includes the energy demand and carbon accounting structure utilized by Böhringer et al. (2011). The added heterogeneous-firms formulation follows directly from Balistreri and Rutherford (forthcoming). Appendix A of this paper offers a derivation of the heterogeneous-firms specific equilibrium conditions, and we offer a non-technical overview of the new theory in the text that follows. ${ }^{1}$

The simulation model is calibrated to an aggregation of the GTAP 7 data. We include nine regions, eight production sectors, and three primary factors of production. Table 1 shows the regions and sectors included. The first six regions are important players in the formation of carbon policy. The Europe aggregate region includes the European Union and all European FTA partners. The rest of Annex 1 aggregate region includes Canada, Japan, Australia, New Zealand, Turkey, Belarus, and the Ukraine. The energy-exporting region (EEX) includes the oil rich Middle Eastern, African, and South American countries (roughly consistent with OPEC nations). The remainder of the world is divided into two aggregates based on World Bank income classifications.

Our aggregation of goods (or production sectors) reflects the minimal set of goods necessary for our analysis of carbon policy and border adjustments applied to energy intensive and trade exposed sectors. The commodity aggregation include three fuels (OIL, GAS, and COL), where the purchase of a fuel indicates emissions of $\mathrm{CO}_{2}$ based on the carbon content of the fuel. The crude oil sector (CRU) is tracked, which provides the input for the oil refining sector. The final energy good is electricity (ELE). We also include the transportation sector because of its emis-

\footnotetext{
${ }^{1}$ As a note to reviewers, the forthcoming handbook chapter, Balistreri and Rutherford (forthcoming), is available at the following web address: http://inside.mines.edu/ ebalistr/hndbook/hndbook.html.
} 
Table 1: Scope of the Empirical Model

\begin{tabular}{|c|c|c|c|c|c|}
\hline \multicolumn{2}{|c|}{ Regions: } & \multicolumn{2}{|c|}{ Goods: } & \multicolumn{2}{|c|}{ Factors: } \\
\hline EUR & Europe & OIL & Refined oil products & LAB & Labor \\
\hline USA & United States & GAS & Natural Gas & CAP & Capital \\
\hline RUS & Russia & ELE & Electricity & RES & Natural Resources \\
\hline RA1 & Rest of Annex 1 & COL & Coal & & \\
\hline $\mathrm{CHN}$ & China & CRU & Crude Oil & & \\
\hline IND & India & EIT & Energy Intensive & & \\
\hline EEX & Energy Exporting & TRN & Transportation & & \\
\hline MIC & Middle-High Income, n.e.c. & $\mathrm{AOG}$ & All other goods & & \\
\hline LIC & Low Income Countries, n.e.c. & & & & \\
\hline
\end{tabular}

sions intensity and important role as an input to international trade. We aggregate the energy intensive and trade exposed sectors into, EIT, which includes ferrous and non-ferrous metals, non-metallic minerals production, chemicals, rubber, and plastics. The final sector is the catch all AOG sector which includes other manufactured products, agriculture, and services.

In Table 1 we also list the primary factors of production: labor, capital, and resources. The resource inputs to fossil fuel extraction (the GAS, COL, and CRU sectors) is sector specific. The elasticity of substitution between the sector-specific resource and other inputs controls the supply elasticity in these sectors (see Böhringer and Rutherford (2011), Appendix D). How fuel prices respond to climate policy is largely determined by the calibrated supply elasticity. This can be an important channel for leakage that is induced by lower fuel prices faced by unregulated regions. Models that do not consider sector-specific resource inputs can generate supply responses that are inconsistent with econometric evidence, and therefore understated fuelprice induced leakage.

Different commodities within the model have different trade treatments. Our intent is to balance empirical relevance with a relatively clean environment to examine the impact of the structural innovation. The innovative heterogeneous-firms structure is only applied to the energy intensive manufacturing sector (EIT). This isolates the structural variation on a specific, 
but relatively important, sector. International trade in crude oil (CRU) is assumed to follow a homogenous goods treatment, so the law of one price (net of trade and transport) holds for CRU. ${ }^{2}$ All other traded goods are assumed to follow the standard Armington treatment of trade in regionally differentiated goods. The remainder of this section focuses on a non-technical description of the heterogeneous-firms treatment of the EIT sector. The derivation of the algebraic conditions can be found in Appendix A and a more detailed derivation is offered by Balistreri and Rutherford (forthcoming).

Melitz (2003) suggests a model of international trade in which firms engage in monopolistic competition within and across borders. The purchasers of goods have a preference for variety, and each firm is assumed to provide a unique (although symmetric) variety. Formally, we assume a Dixit-Stiglitz aggregation of firm-level output in the EIT sector. ${ }^{3}$ Firms differ (are heterogeneous) in that they face different production costs. Firms operate under a simple technology where a composite input is used on a fixed cost and a constant marginal cost. Marginal cost, however, is dependent on a firm-specific productivity draw, $\varphi_{\omega}$, where $\omega \in \Omega$ indexes firms (or, equivalently, varieties). The productivity draws are assumed to come from a Pareto distribution with curvature $a$ and lower support $b$. The cumulative distribution is given by $G(\varphi)=1-\left(\frac{b}{\varphi}\right)^{a}$. If we let $f_{r s}$ indicate the fixed cost associated with supplying from source region $r$ into market $s$, the total cost associated with producing $q_{r s \omega}$ units in $r$ for market $s$ by firm $\omega$ is given by $f_{r s}+q_{r s \omega} / \varphi_{\omega}$. Under this structure, of heterogeneous technologies across firms, competitive selection becomes a key component of the equilibrium.

Competitive selection within the Melitz structure depends on the profitability of firms across various markets. Initially firms decide if they will enter the market by paying to see their real-

\footnotetext{
${ }^{2}$ Many empirical climate-policy models adopt a homogeneous goods formulation for crude oil, reflecting the high substitutability between crude oil sourced from different regions. This assumption is supported by the empirical estimates made by Balistreri et al. (2010a), who estimate an Armington elasticity for crude oil of 23. An estimated substitution elasticity of 23 is arguably close to a perfect substitutes model and high enough to justify a homogeneous goods treatment.

${ }^{3}$ Dixit and Stiglitz (1977) formalized the love-of-variety specification of preferences that forms the foundation for most contemporary monopolistic competition models.
} 
ization of $\varphi_{\omega}$. The model includes a free-entry condition which balances the value of the entry payment with expected profits. Once a firm enters the payment is sunk and has no further impact on the firm's decisions.

Give a productivity realization, $\varphi_{\omega}$, the firm must then make a decision on how much output to produce (if any) and in which markets it will participate. Some firms drawing a low $\varphi_{\omega}$ will find that their costs are so high that it is unprofitable to operate in any markets. These firms simply exit. Other firms, with a higher $\varphi_{\omega}$ draw, will observe their firm-level demand and find it profitable to operate in their domestic market (presuming that $f_{r r}<f_{r s} \forall r \neq s$ ). For firms with an even higher $\varphi_{\omega}$ draw it may be profitable to produce output for the domestic market and to produce output for export markets. A firm that operates in multiple markets carries the same $\varphi_{\omega}$ but faces the market specific fixed operating cost $f_{r s}$. The condition that determines the competitive selection of firms into the various bilateral markets is the zero-cutoff-profit condition. This condition balances the bilateral fixed cost with the profits of the marginal firm supplying the market. Firms drawing a productivity above the marginal firm's productivity will supply the market; where as, firms drawing a lower productivity will not. Melitz (2003) derives the relevant free-entry and zero-cutoff-profits conditions necessary to fully specify the trade equilibrium. In Balistreri and Rutherford (forthcoming) we develop the methodology necessary to adopt the Melitz theory for application in large scale policy simulation models.

\section{Calibration}

With the exception of the heterogeneous-firms sector we adopt a standard multi-sector multiregion computable general equilibrium (CGE) calibration. Nested constant elasticity of substitution (CES) expenditure and production functions are calibrated to the GTAP 7 global social accounts, and we adopt the nesting structure and elasticities proposed by Böhringer and Rutherford (2011). A few modifications are needed, however, for the EIT (heterogeneous-firms) sector. 
Differentiation is at the firm level, so we eliminate the import-import versus import-domestic nesting. The production technologies for EIT are unaltered, but the output is interpreted as a composite input available to the firms facing the increasing returns technology. The sunk, fixed, and all variable costs are incurred in terms of expenditures on the composite input.

The heterogeneous-firms formulation also requires a set of additional parameters that do not appear in the Armington model. We establish the elasticity of substitution between varieties, $\sigma_{E I T}=3.8$, based on the plant-level analysis of Bernard et al. (2003); and the parameters of the Pareto distribution, $a=4.6$ and $b=0.2$, based on the structural estimation by Balistreri et al. (2011). We also use Balistreri et al. (2011) to give us a rough guess of the bilateral fixed costs $\left(f_{r s}\right)$, although our experiments are not sensitive to these values. ${ }^{4}$ The calibration proceeds by using the fixed cost estimates and the substitution elasticity to establish the revenues of the average firm operating in each bilateral market $\left(\tilde{p}_{r s} \tilde{q}_{r s}\right)$ based on the zero-cutoff-profit condition, and a typical choice of units such that the cost of a unit of the composite input is one. With average-firm revenues established we can calculate the benchmark measure of the number of operating firms $\left(N_{r s}\right)$, by noting that the value of trade from the accounts must equal the number of firms times firm-level revenues.

A measure of the total number of firms entered $\left(M_{r}\right)$ can be chosen at an arbitrary level above the maximum number of operating firms (we must have $N_{r s} / M_{r}>1$ ). The free-entry condition along with the choice of scale on $M_{r}$ establishes the sunk cost payment. Again, this is a choice of scale and does not impact our counterfactual analysis. With the ratios of the operating to entered firms established we can establish the calibrated productivity of the average firm in each market, $\tilde{\varphi}_{r s}$ from the elasticity and the parameters of the Pareto distribution. Choosing composite units such that the price is one, we can recover the average-firm price, $\tilde{p}_{r s}$, and

\footnotetext{
${ }^{4}$ The experiments are insensitive to the scale and distribution of benchmark fixed costs because the elasticity, alone, establishes the markup over marginal cost. Higher assumed values of $f_{r s}$ must directly indicate higher revenues per firm, and this simply means a lower, calibrated, initial number of firms. Assumptions about operating fixed costs simply scale our measure of the number of firms.
} 
Table 2: Scenario variations

\begin{tabular}{ccc} 
Structure & Policy & Coalition \\
\hline ARM_Low & BAU & EUR \\
ARM_High & REF & A1xR \\
Melitz & BCA & A1xR_CHN \\
\hline
\end{tabular}

therefore quantity from the established firm-level revenues. The only remaining parameter in the calibration is a value for the unobserved bilateral trade costs (or equivalently the bilateral taste bias parameter). These are recovered from the optimal markup condition. ${ }^{5}$ Balistreri and Rutherford (forthcoming) provide a more detailed account of the calibration procedure and how it relates to a standard Armington calibration.

\section{Scenarios}

Maintaining focus on our objective of highlighting the impact of the structural treatments we adopt a small number of scenarios that are consistent with the model comparison scenarios. These include three structural treatments, three policy cases (including business as usual), and sensitivity over three potential subglobal coalitions. Table 2 outlines the scenario variations. The base year for our comparative-static comparison is 2004, consistent with the raw GTAP 7 data. Variations on the projected base year (2004 versus 2020) and an exploration of how much carbon leakage is driven by the fossil fuel price channel are considered in the broader model comparison study and in other specific papers in this special issue. For the purpose of this paper we aim at a direct comparison of the structural assumptions, and, thus, concentrate on a few basic scenarios.

The first structure is a standard Armington model, Armington (Low), where "Low" refers

\footnotetext{
${ }^{5}$ Balistreri and Rutherford (forthcoming) explain the irrelevance of choosing to interpret the calibration residual as an unobserved iceberg cost factor or an idiosyncratic bilateral taste bias in a situation where there is no explicit structure assumed for unobserved costs and these costs are not manipulated in the course of counterfactual experiments.
} 
to the elasticity of substitution between regional varieties in the EIT sector, $\sigma_{E I T}=3.8$. This substitution elasticity is based on the value adopted in the heterogeneous-firms formulation. In the second treatment, Armington (High), we maintain the Armington structure of trade but increase the elasticity of substitution to $\sigma_{E I T}=5.6$, which is equal to the heterogeneousfirms Pareto shape parameter plus one $(a+1) .{ }^{6}$ In the third treatment, Melitz, we adopt the heterogeneous-firms trade structure for the EIT sector. The trade response parameters under the Melitz treatment are set at the values adopted and estimated by Balistreri et al. (2011): $\sigma_{E I T}=3.8$ and $a=4.6$. The three treatments are intended to offer a comparison of the Melitz structure to variations in standard Armington models that might adopt varying degrees of trade response.

The policy scenarios that we consider include a no-policy business as usual case, a reference subglobal carbon policy case, and a case where the subglobal carbon policy is augmented by border adjustments. The policy scenarios are as follows:

- BAU: business as usual (no policy) case;

- REF: reference policy, which is a reduction in global emissions equal to $20 \%$ of coalition emissions; ${ }^{7}$ and

- BCA: full border carbon adjustment scenario, where the coalition meets the emissions target but also imposes embodied-carbon tariffs and export rebates on energy intensive trade.

\footnotetext{
${ }^{6}$ Balistreri et al. (2010b) and Arkolakis et al. (2012) show that a simplified Armington model can generate trade responses equivalent to a Melitz model if the Armington elasticity is set equal to the Pareto shape parameter plus one $(a+1)$. Of course, the empirically relevant features of our climate-policy model (multiple sectors, multiple inputs including intermediates, and rent generating trade distortions) breaks the Arkolakis et al. (2012) tight equivalence results (see Balistreri et al. (2011)). Setting $\sigma_{E I T}=a+1$ in the Armington (High) instance indicates that the differences we show in our results are robust over a range of Armington elasticities, which includes the Arkolakis et al. (2012) equivalence value. An elasticity of substitution of 5.6 is also generally consistent with the import-import elasticities provided in the GTAP data for the energy-intensive subaggregate sectors. The GTAP elasticities are reported in Dimaranan et al. (2006).

${ }^{7}$ The cap on coalition emissions is endogenously determined to meet the overall global target. This offers a fair welfare comparison over policy scenarios and structural assumptions, because the environmental impact of the policy is held fixed while there may be significant variation in the leakage rates.
} 
In the reference scenario, the coalition emissions reductions are met at least cost in terms of a comprehensive coverage of all sources and an equalized emissions price across all coalition countries. In the full border adjustment scenario, the sectors subject to the border adjustments are EIT and OIL (refined petroleum) due to the high volume of trade in these products and their emissions intensity.

The embodied carbon, which forms the tax base for the border adjustments, is calculated as direct production emissions and the indirect emissions associated with electricity inputs. ${ }^{8}$ As an alternative to our limited measure of embodied carbon, one might consider using multiregion input-output techniques to calculate the full indirect carbon content. Others contributing to this special issue explore model sensitivity to different measures of embodied carbon. Our method captures most of the associated emissions and is consistent with the standardized model comparison scenario treatment. Policies based on direct and associated electricity emissions are arguably more realistic, given the administrative, monitoring, and legal costs associated with carbon based border charges. Further, notice that under a heterogeneous firms theory the input-output method is flawed because the average export firm is unlikely to have the same emissions profile as the average firm within an industry. ${ }^{9}$ Input-output measures of the embodied carbon in trade will be overstated, to the extent that the heterogeneous-firms model predicts that it is efficient (high productivity) firms that engage in international trade.

We focus on a coalition that includes the Annex 1 countries (except Russia), but we also consider variations were we reduce the coalition to only include Europe and expand the Annex 1 coalition to include China. The labels associated with these coalitions are as follows: EUR, A1xR, A1xR_CHN. These coalitions are consistent with the coalition variations included in the broader model comparison exercise. Table 2 summarizes the scenario variations that we include in this

\footnotetext{
${ }^{8}$ The OIL sector is not taxed on the carbon content of the actual product, just the carbon emissions associated with its production (refining). This is the correct treatment to avoid a double taxation of the carbon content of the fuel (both at the border and at the point that it is burned).

${ }^{9}$ Batrakova and Davies (2010) provide evidence that selection into export status is consistent with lower fuel consumption by high fuel intensity firms.
} 
paper.

\section{Results}

We find important quantitative and qualitative differences between the Armington and Melitz treatments. One of the most interesting differences that we see in the results concerns burden shifting. To some degree the Armington model limits trade responses relative to the initial calibration point and fails to account for the productivity changes predicted by the Melitz structure. In our Armington treatment emissions reductions by the A1xR coalition imposes welfare losses across the non-coalition even in the absence of border adjustments. This is a robust finding across Armington models that appear in the literature. In the Melitz simulations, however, we show welfare gains for the non-coalition. Coalition policies offer a competitive advantage for energy intensive production in non-coalition regions. Relative to an Armington structure, the intra-industry reallocation of non-coalition resources into more productive firms increases overall productivity. This non-coalition productivity boost translates into overall non-coalition welfare improvements. Figure 1 illustrates this key difference across the structural assumptions. ${ }^{10}$

Another interesting qualitative difference to notice in Figure 1 is that, under the Melitz structure, coalition welfare remains below its BAU level when border measures are imposed. In contrast the Armington structures indicates small coalition gains in the BCA scenario. The explanation for this difference can be traced to differences in optimal tariffs across structures. It is well known that the Armington structure implies large optimal tariffs (even for relatively small countries). ${ }^{11}$ In an Armington model regions supply unique varieties to the world market at marginal cost leaving significant room for the policy authority to exercise regional market power through

\footnotetext{
${ }^{10}$ Consistent with the standards established in the model comparison exercise, welfare for a group of regions is calculated as follows. We sum the values of household consumption across regions and deflate the resulting value by a world price index. The price index is the consumption-weighted average of regional unit-expenditure indexes.

${ }^{11}$ This feature of Armington models is critiqued by Brown (1987) and Balistreri and Markusen (2009).
} 
Figure 1: Coalition and non-coalition policy burdens (A1xR Coalition)

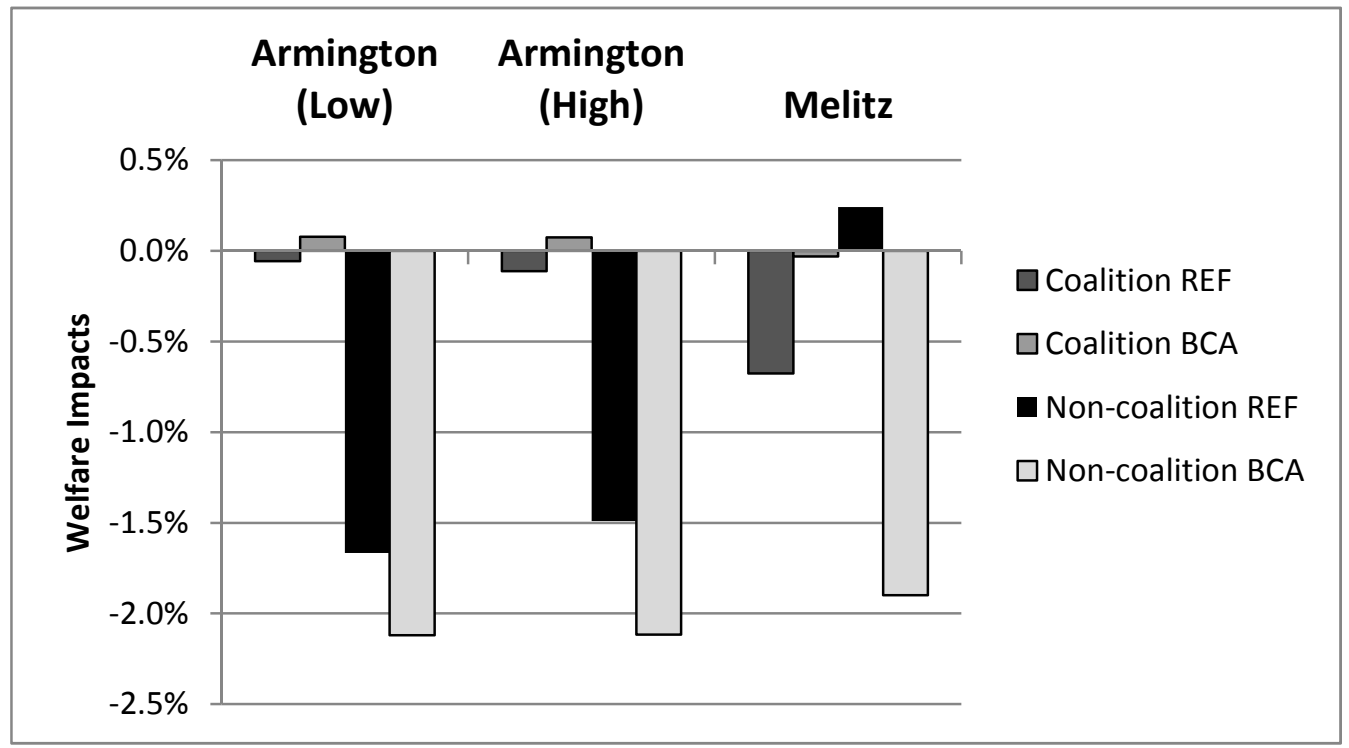

a beggar-thy-neighbor tariff. Balistreri and Markusen (2009) explain, however, that this is not the case in monopolistic competition models. Under monopolistic competition firms set export prices according to an optimal markup, which reduces the optimal tariff. With a lower optimal tariff the coalition is less able to extract rents from the non-coalition. The coalition and the non-coalition suffer under the BCA scenario, although the majority of the burden still falls on non-coalition regions. In fact, the slight increase in coalition welfare in the Armington BCA runs is driven by the choice of deflator (see footnote 10), because the welfare as measured by equivalent variation of each of the component regions falls slightly. Tables 3 and 4 report the true equivalent variation welfare impacts decomposed by region. Welfare is reported as changes in money metric household utility from private consumption. It is the value of household consumption deflated by the true-cost-of-living index (the unit expenditure index) for that region.

We see in Table 3 that the Melitz structure indicates individual non-coalition regions benefitting from the REF carbon policy, except for Russia. Even the EEX region, which is heavily 
Table 3: Reference (REF) Scenario Regional Welfare Impacts (A1xR Coalition, \% EV)

\begin{tabular}{lrccc} 
Region & BAU $(\$ B)$ & Armington(Low) & Armington(High) & Melitz \\
\hline USA & 8,267 & -0.19 & -0.22 & -0.60 \\
EUR & 8,075 & -0.35 & -0.38 & -0.69 \\
RA1 & 3,914 & -0.40 & -0.44 & -1.35 \\
MIC & 2,330 & -0.13 & -0.05 & 1.24 \\
CHN & 796 & -0.33 & -0.29 & 0.26 \\
EEX & 848 & -2.28 & -2.14 & 0.37 \\
IND & 434 & 0.35 & 0.36 & 0.37 \\
LIC & 349 & -0.34 & -0.32 & 0.10 \\
RUS & 292 & -3.78 & -3.53 & -0.93 \\
\hline
\end{tabular}

Table 4: Border Carbon Adjustment (BCA) Scenario Regional Welfare Impacts (A1xR Coalition, $\% \mathrm{EV})$

\begin{tabular}{lrccc} 
Region & BAU (\$B) & Armington(Low) & Armington(High) & Melitz \\
\hline USA & 8,267 & -0.14 & -0.15 & -0.29 \\
EUR & 8,075 & -0.27 & -0.26 & -0.19 \\
RA1 & 3,914 & -0.33 & -0.35 & -0.63 \\
MIC & 2,330 & -0.19 & -0.17 & 0.29 \\
CHN & 796 & -0.40 & -0.43 & -0.79 \\
EEX & 848 & -2.68 & -2.67 & -2.21 \\
IND & 434 & 0.29 & 0.26 & 0.15 \\
LIC & 349 & -0.43 & -0.45 & -0.76 \\
RUS & 292 & -5.00 & -5.11 & -6.00 \\
\hline
\end{tabular}

dependent on energy exports, benefits due to the expansion of its energy intensive production sectors. In all of the non-coalition regions the Melitz structure indicates substantial competitive effects as energy intensive production expands.

Figure 2 reports the impacts on non-coalition EIT production under the REF scenario. ${ }^{12}$ We see dramatic expansion of EIT production in the energy exporting regions (EEX and RUS), but the total non-coalition change is dominated by the large players. In the benchmark $43 \%$

\footnotetext{
${ }^{12}$ In Figure 2 for the Melitz model we report percentage changes in composite input supply. This gives us a measure of output that is comparable with the output changes in the constant-returns Armington models. Given productivity increases a measure of firm-level output would indicate even larger changes.
} 
Figure 2: Non-coalition EIT output response (A1xR coalition, REF scenario)

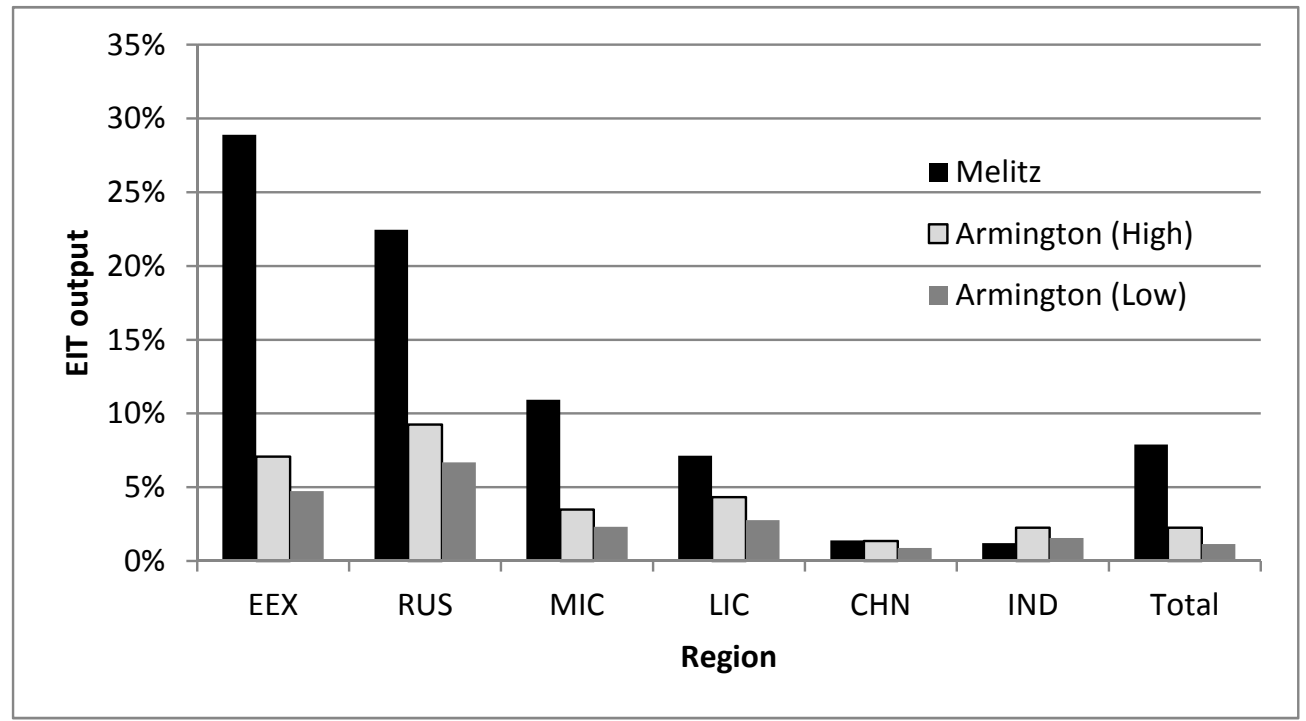

and $36 \%$ of non-coalition EIT production takes place in China and the Middle-income regions. Overall non-coalition production of EIT expands by $8 \%$, which is significantly higher than the $1 \%$ and $2 \%$ observed under the Armington Low and Armington High structures.

The large impacts on the global distribution of energy intensive production that we observe under the Melitz structure translate into larger leakage rates. Under the A1xR coalition, for example, the carbon leakage rate under the Melitz treatment is $19 \%$, where as under the Armington Low and Armington High treatments it is $13 \%$ and $14 \%$. Our results indicate that the competitive channel for carbon leakage might be more important than previously estimated using Armington models. However, the enhanced trade response does indicate that border measures are more effective. With full border adjustments applied (the BCA scenario), leakage rates are roughly cut in half with Melitz trade, while only reduced by about one third under the Armington structure. Table 5 reports the leakage rates. The REF leakage rates are much higher under the Melitz structure, but because border adjustments are more effective the overall BCA leakage rates are similar. One interesting result shown in Table 5 is that under the Melitz struc- 
Table 5: Carbon Leakage Rates (\%) decomposed by region (A1xR Coalition)

\begin{tabular}{|c|c|c|c|c|c|c|}
\hline & \multicolumn{2}{|c|}{ Armington(Low) } & \multicolumn{2}{|c|}{ Armington(High) } & \multicolumn{2}{|c|}{ Melitz } \\
\hline & $\mathrm{REF}$ & $\mathrm{BCA}$ & $\mathrm{REF}$ & $\mathrm{BCA}$ & $\mathrm{REF}$ & BCA \\
\hline Total & & & & & & \\
\hline Leakage Rate: & 12.5 & 9.4 & 13.5 & 9.3 & 19.1 & 9.5 \\
\hline By Region: & & & & & & \\
\hline MIC & 4.3 & 4.1 & 4.5 & 4.2 & 5.9 & 5.0 \\
\hline EEX & 2.5 & 1.7 & 2.8 & 1.8 & 5.7 & 2.6 \\
\hline CHN & 2.4 & 1.9 & 2.6 & 1.8 & 2.6 & 1.5 \\
\hline RUS & 1.6 & 0.2 & 1.8 & 0.2 & 3.3 & -0.6 \\
\hline IND & 1.0 & 0.8 & 1.0 & 0.8 & 0.9 & 0.7 \\
\hline LIC & 0.7 & 0.6 & 0.8 & 0.6 & 0.8 & 0.3 \\
\hline
\end{tabular}

ture border adjustments actually drive the leakage rate for Russia negative. Energy intensive production in Russia suffers from the border adjustments and once we account for the competitive selection of firms and the adverse income effects overall Russian emissions go down.

Figure 3 gives an indication of the overall scope of the A1xR-coalition scenario in terms of $\mathrm{CO}_{2}$ price. The coalition cap adjusts to compensate for leakage (so the overall global emissions target is met). This is reflected in higher $\mathrm{CO}_{2}$ prices under the Melitz structure, and lower $\mathrm{CO}_{2}$ prices once border adjustments are added. In the border adjustment scenarios the leakage rates are roughly consistent, and this indicates roughly consistent carbon prices (all about \$42). This indicates that we are effectively controlling energy demand in the experiments that vary the trade structure. The differences that we observe across structures are not attributed to fundamentally different energy responses. Rather the differences that we observe across structures are driven by trade responses and the competitive selection of firms.

In the remainder of the results we explore the sensitivity of our central findings to coalition size. As we scale the coalition size down to only include Europe (which significantly reduces the global emissions target), the key burden shifting results are muted but not eliminated. Fig- 
Figure 3: Carbon prices over different structures (A1xR coalition)

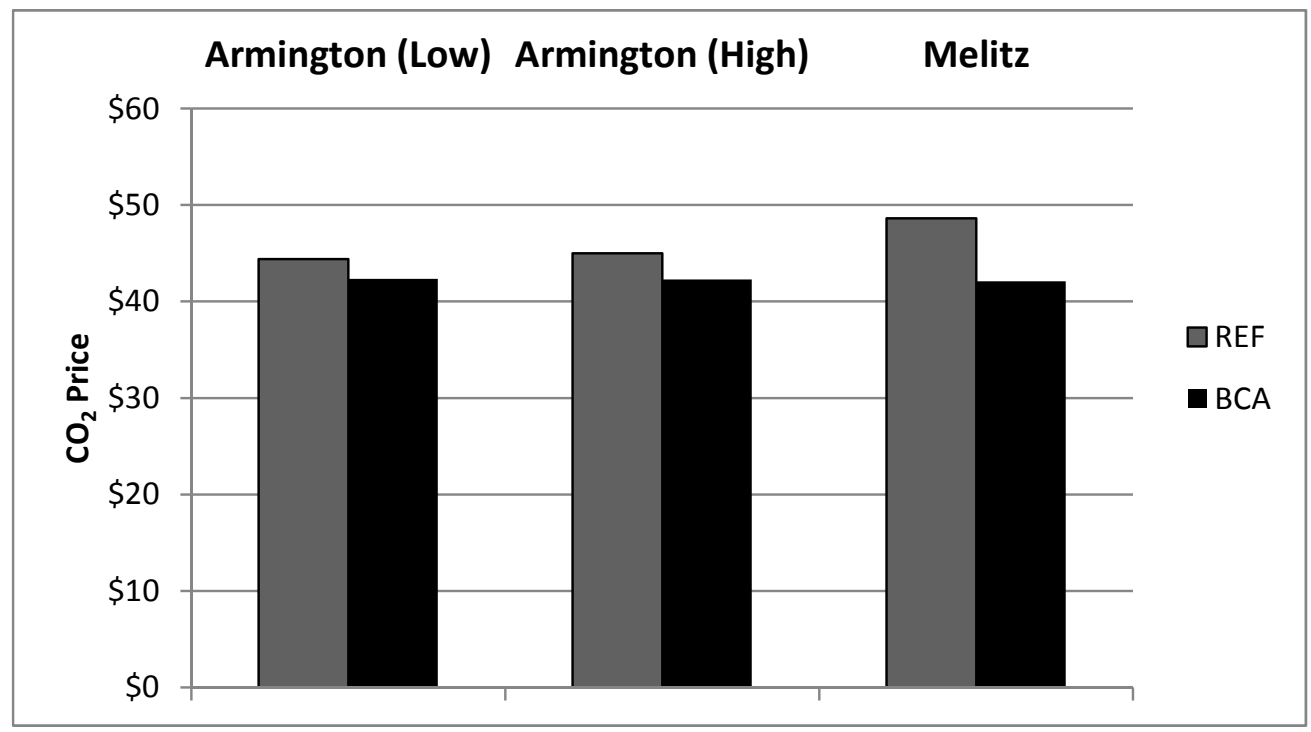

ure 4 shows that, although the non-coalition does not benefit under the Europe only reference scenario, it faces smaller losses. In contrast, when the coalition expands to include China the non-coalition benefits under the reference scenario rise rather dramatically. Expansion of noncoalition energy-intensive production intensifies the greater is the regulatory coverage. The productivity expansion and net entry of new varieties into the world market by non-coalition firms becomes increasingly more important the more comprehensive is the coalition coverage. Border adjustments indicate an interesting pattern of burden shifting. The cost to the coalition of imposing border adjustments is monotonically increasing with coalition size (starting with benefits and moving to costs), and the cost to the non-coalition of the border adjustments reaches a max and then diminishes once the coalition becomes large.

An important lesson here is that gradualism to a global coalition is unlikely. Nations outside the coalition have more and more to lose by joining the coalition in the case without border adjustments. If the coalition tries to use border adjustments strategically, to persuade noncoalition nations to join, the efficacy of the border adjustments to punish the non-coalition is 
Figure 4: Sensitivity of burden shifting to coalition size (Melitz structure)

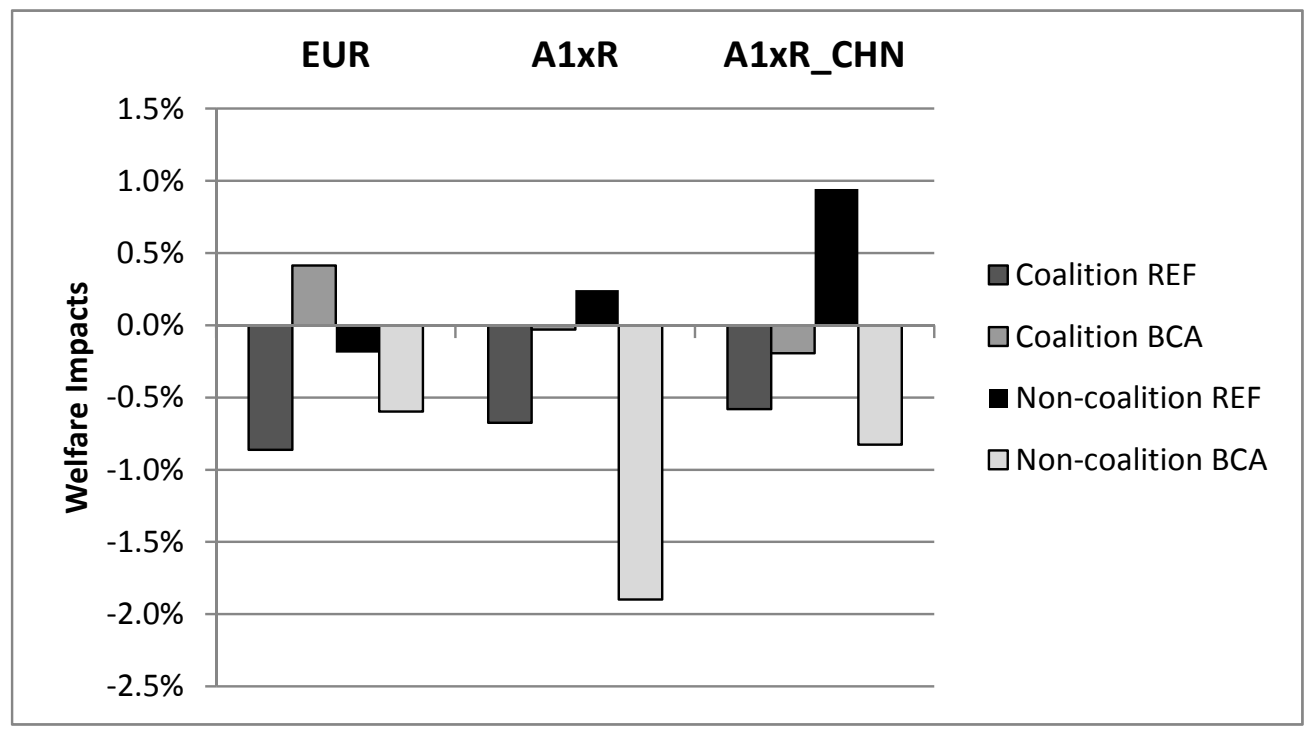

diminishing. Moving from the $\mathrm{A} 1 \mathrm{xR}$ coalition to the $\mathrm{A} 1 \mathrm{xR} \_\mathrm{CHN}$ coalition we see that the welfare cost of the border adjustments on the non-coalition are reduced, while the welfare costs to the coalition are increased. The national incentives do not seem to favor evolution toward a global coalition.

Figure 5 indicates the carbon price sensitivity to the coalition size. As the coalition expands the global target expands, but the opportunity to meet the target with low cost emissions reductions also expands. We model the policy as a uniform carbon tax imposed on all coalition emissions, so marginal abatement costs are equalized across coalition sources. Reducing the coalition to only include Europe increases the carbon price because Europe is a relatively high abatement cost region. In contrast carbon prices fall with the inclusion of China which is a relatively low abatement cost region. Carbon prices are lower under border adjustments as the overall coalition cap is reduced to compensate for lower leakage rates. This effect is reduced with larger coalitions, because the differential between border adjustment and non-border adjustment leakage rates falls. Figure 6 shows the overall leakage rates across the different coali- 
Figure 5: Sensitivity of carbon price to coalition size and border adjustments (Melitz structure)

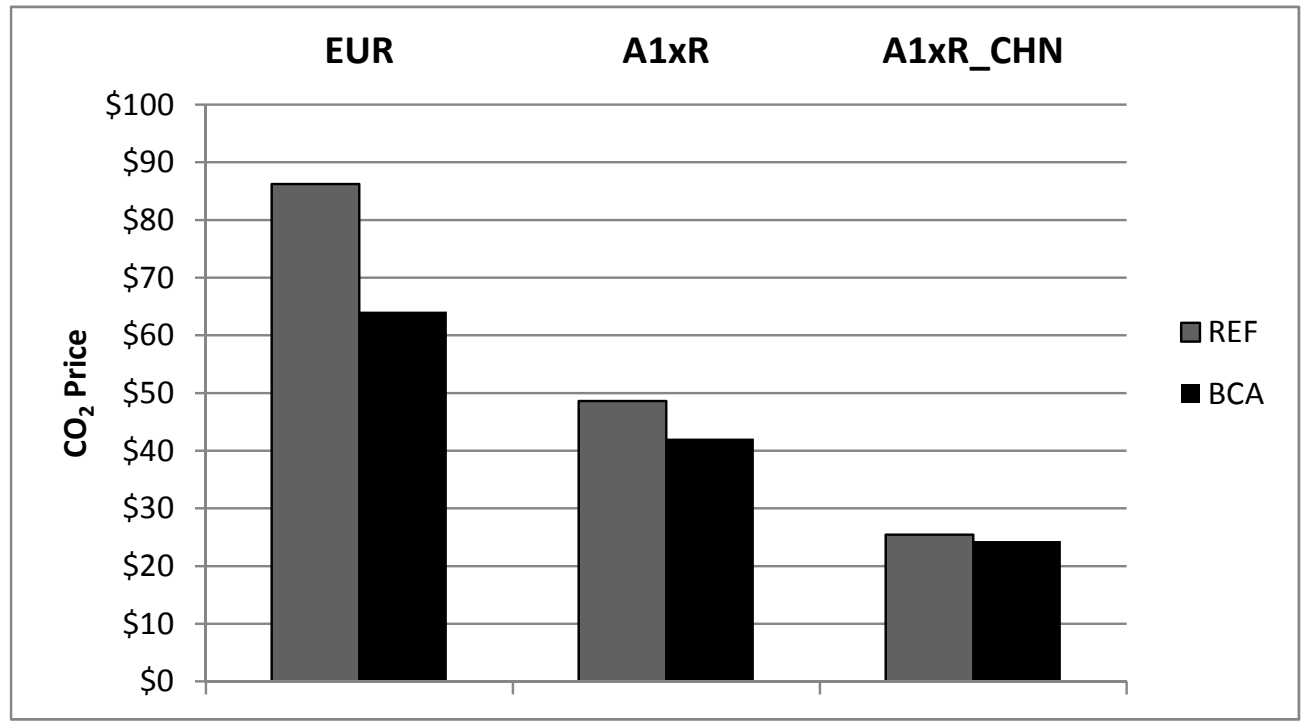

Figure 6: Sensitivity of leakage rates to coalition size and border adjustments (Melitz structure)

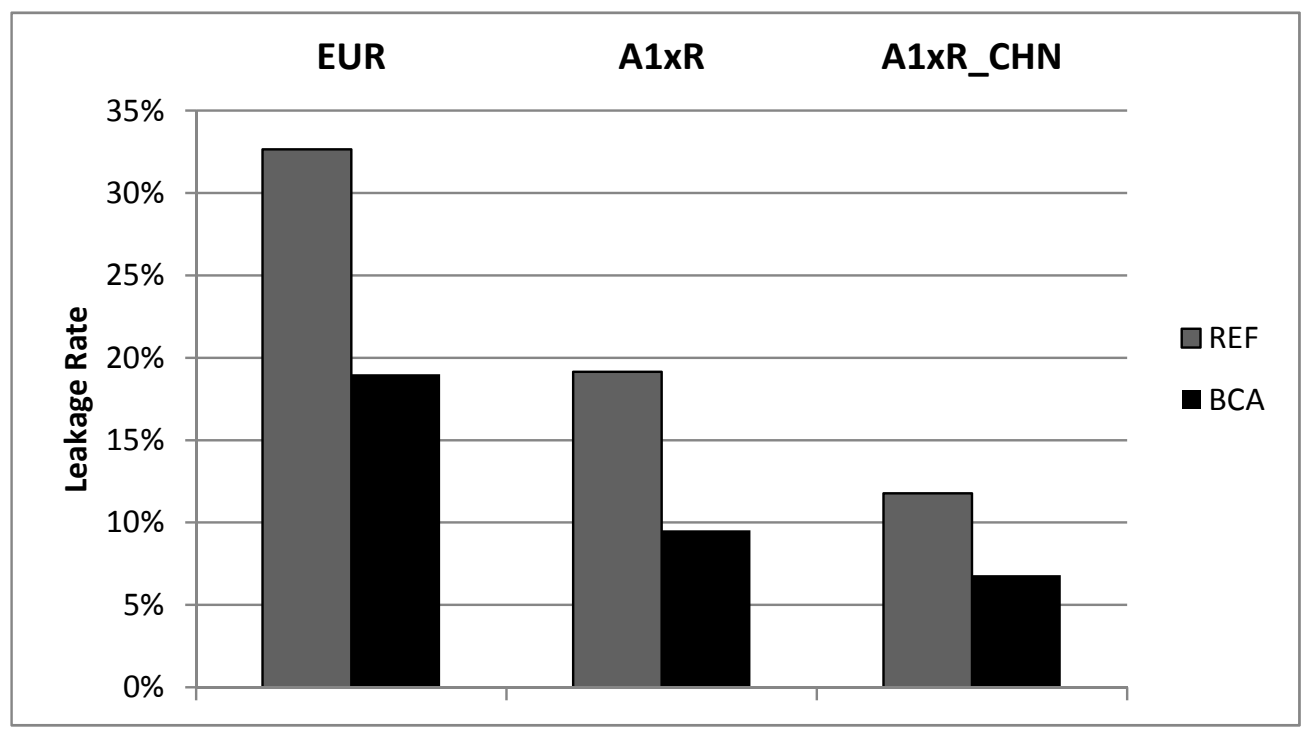


tions. Consistent with our previous results we show high leakage rates (relative to the literature based Armington models), but we also show that border adjustments are more effective at reducing leakage.

\section{Conclusion}

In this paper we consider subglobal carbon policy under a recently proposed alternative trade theory. The theory includes the competitive selection of heterogeneous firms engaged in monopolistic competition and international trade. Our treatment is in contrast to the majority of the climate policy literature, which adopts a perfect competition Armington structure. We assess the sensitivity of conclusions regarding burden shifting, carbon leakage, and the efficacy of border adjustments under the alternative structural assumptions. There is substantial empirical evidence supporting the heterogeneous-firms structure, and to this extent the differences that we find are important considerations for future research. In sum, we find that the heterogeneous-firms structure indicates larger competitive effects, larger leakage rates (but more effective border adjustments), and substantially different conclusions about policy burden shifting.

It is often presumed that regions that opt out of a subglobal agreement will benefit as they enjoy lower fuel prices, enhanced demand for their energy intensive export goods, and the public-good spillovers associated with climate action. Somewhat surprisingly, current modeling exercises show welfare declines for unregulated regions. Clearly, the issue of public benefits from climate action are difficult to quantify. We highlight, however, that the structural assumptions of contemporary models can also be a source of bias on private benefits. We do find that private welfare is driven higher in most non-coalition countries due to competitive effects. We show larger trade responses in the energy intensive goods emphasizing the competitive effects of climate policy. This result is driven by endogenous productivity and entry dynamics that are 
not considered in the standard Armington formulation of trade.

One critical lesson that we bring away from our simulations is that gradualism toward a global coalition is not favored. The more comprehensive is the coalition the more intense are the welfare benefits that accrue to the non-coalition. Outsiders find it more and more costly to join the coalition in terms of giving up their competitive advantage. This is shown at the industry level in Armington models, but under the advanced trade structure we show it at the national or regional welfare level. Border measures might be used to counteract this effect, as the non-coalition suffers under border adjustments. Our results show, however, that the efficacy of border adjustments to reduce non-coalition welfare diminishes under large coalitions. 


\section{References}

Arkolakis, Costas, Arnaud Costinot, and Andrés Rodríguez-Clare (2012) 'New trade models, same old gains?' American Economic Review 102(1), 94-130

Armington, Paul S. (1969) 'A theory of demand for products distinguished by place of production.' Staff Papers-International Monetary Fund 16(1), 159-178

Aw, Bee Yan, Xiaomin Chen, and Mark J. Roberts (2001) 'Firm-level evidence on productivity differentials and turnover in Taiwanese manufacturing.' Journal of Development Economics 66(1), $51-86$

Balistreri, Edward J., and James R. Markusen (2009) 'Sub-national differentiation and the role of the firm in optimal international pricing.' Economic Modelling 26(1), 47 - 62

Balistreri, Edward J., and Thomas F. Rutherford (forthcoming) 'Computing general equilibrium theories of monopolistic competition and heterogeneous firms.' In Handbook of Computable General Equilibrium Modeling, ed. Peter B. Dixon and Dale W. Jorgenson (Amsterdam: Elsevier)

Balistreri, Edward J., Ayed Al-Qahtani, and Carol A. Dahl (2010a) 'Oil and petroleum product Armington elasticities: A new-geography-of-trade approach to estimation.' The Energy Journal31(3), 167 - 179

Balistreri, Edward J., Russell H. Hillberry, and Thomas F. Rutherford (2010b) 'Trade and welfare: Does industrial organization matter?' Economics Letters 109(2), 85 - 87

_ (2011) 'Structural estimation and solution of international trade models with heterogeneous firms.' Journal of International Economics 83(2), 95 - 108

Bartelsman, Eric J., and Mark Doms (2000) 'Understanding productivity: Lessons from longitudinal microdata.' Journal of Economic Literature 38(3), 569-594

Batrakova, Svetlana, and Ronald B. Davies (2010) 'Is there an environmental benefit to being an exporter? Evidence from firm level data.' UCD Center for Economice Reseach Working Paper Series, WP10/07, University College Dublin

Bernard, Andrew B., and J. Bradford Jensen (1999) 'Exceptional exporter performance: Cause, effect, or both?' Journal of International Economics 47(1), 1 - 25

Bernard, Andrew B., Jonathan Eaton, J. Bradford Jensen, and Samuel Kortum (2003) 'Plants and productivity in international trade.' American Economic Review 93, 1268-1290

Böhringer, Christoph, and Thomas F. Rutherford (2011) 'General equilibrium analysis based on GTAP in GAMS: Method, data, application.' Technical Report, University of Oldenburg and ETH Zürich 
Böhringer, Christoph, Jared C. Carbone, and Thomas F. Rutherford (2011) 'Embodied carbon tariffs.' Working Paper 17376, National Bureau of Economic Research

Brown, Drusilla K. (1987) 'Tariffs, the terms of trade, and national product differentiation.' Journal of Policy Modeling 9(3), 503-526

Bustos, Paula (2011) 'Trade liberalization, exports and technology upgrading: Evidence on the impact of MERCOSUR on Argentinian firms.' American Economic Review 101(1), 304-340

Dimaranan, Betina, Robert McDougall, and Thomas Hertel (2006) 'GTAP 6 data base documentation - Chapter 20: Behavioral parameters.' Technical Report, Center for Global Trade Analysis, Purdue University

Dixit, Avinash K., and Joseph E. Stiglitz (1977) 'Monopolistic competition and optimum product diversity.' The American Economic Review 67(3), 297-308

Martin, Leslie A. (2012) 'Energy efficiency gains from trade: greenhouse gas emissions and india's manufacturing firms.' Department of Agricultural and Resource Economics, University of California Berkley

Melitz, Marc J. (2003) 'The impact of trade on intra-industry reallocations and aggregate industry productivity.' Econometrica 71(6), 1695-1725

Roberts, Mark J., and James R. Tybout (1997) 'The decision to export in colombia: An empirical model of entry with sunk costs.' The American Economic Review 87(4), 545-564

Trefler, Daniel (2004) 'The long and short of the Canada-U.S. Free Trade Agreement.' American Economic Review 94(4), 870-895 


\section{A Appendix: Heterogeneous-firms Trade Theory}

In this appendix we describe the heterogeneous-firms trade structure as it is applied to the EIT sector in this study. The structure described here replaces the Armington aggregation that appears in a standard computable general equilibrium (CGE) model. To simplify our description we take as given regional demand for the EIT composite of firm level varieties. This is given by the variable $Q_{E I T, r}$ which includes intermediate demand and final demand for EIT in region $r$. In a standard CGE model $Q_{E I T, r}$ would represent demand for the Armington composite of regional varieties, but in our case it is demand for the Dixit-Stiglitz composite of firm-level varieties from around the world. In addition, we take as given the upstream supply of the composite input to EIT firms in each region. Denote this supply $Y_{E I T, r}$. In a standard CGE model $Y_{E I T, r}$ would represent industry output. In the present structure, however, $Y_{E I T, r}$ is demanded by the heterogeneous firms for use in covering sunk costs, bilateral fixed costs, as well as operating variable costs.

The composite used in final and intermediate demand is assumed to be made up of a continuum of firm varieties. Using the dual form we specify the Dixit-Stiglitz price index for this composite commodity in region $s$. Let $\omega_{r s} \in \Omega_{r}$ index the differentiated EIT products sourced from region $r$ shipped into region $s$. Let $p_{r s}\left(\omega_{r s}\right)$ be the gross price of variety $\omega_{r s}$ and let $\sigma_{E I T}$ be the constant elasticity of substitution between the varieties. The price index is given by

$$
P_{s}=\left[\sum_{r} \int_{\omega_{r s}}\left[p_{r s}\left(\omega_{r s}\right)\right]^{1-\sigma_{E I T}} d \omega_{r s}\right]^{\frac{1}{1-\sigma_{E I T}}}
$$

Melitz (2003) simplifies the price index by specifying the price set by a representative firm from region $r$ supplying market $s$. Denote this price $\tilde{p}_{r s}$ which is the gross price set by the firm engaged in exporting from $r$ to $s$ that has the CES-weighted average productivity. Using this price, and scaling it up by the measure of the number of firms, $N_{r s}$, operating on the $r$ to $s$ link, we 
have Melitz's simplified price index:

$$
P_{s}=\left[\sum_{r} N_{r s}\left(\tilde{p}_{r s}\right)^{1-\sigma_{E I T}}\right]^{1 /\left(1-\sigma_{E I T}\right)},
$$

Notice that trade costs and policy instruments do not enter equation (2), which is consistent with our definition of $\tilde{p}_{r s}$ as gross of these margins. Trade costs and trade policy distortions will enter the optimal markup equation. The quantity supplied by the average firm must satisfy demand which is derived by applying the envelope theorem to the dual form of the aggregation:

$$
\tilde{q}_{r s}=Q_{E I T, s}\left(\frac{P_{s}}{\tilde{p}_{r, s}}\right)^{\sigma_{h}} .
$$

Consider a small profit-maximizing firm facing this demand. Consistent with the largegroup monopolistic competition assumption, the small firm does not consider its impact on the aggregate price index $\left(P_{s}\right)$. Now, let $c_{r}$ indicate the price of the composite EIT input in region $r$, and let $\tilde{\varphi}_{r s}$ indicate the productivity of the firm (such that the marginal cost of production is $\left.c_{r} / \tilde{\varphi}_{r s}\right)$. Setting marginal cost equal to marginal revenue yields the optimal markup condition for the average firm:

$$
\tilde{p}_{r s}=\frac{c_{r} \tau_{r s}\left(1+t_{r s}\right)}{\left(1-1 / \sigma_{E I T}\right) \tilde{\varphi}_{r s}}
$$

where we introduce $\tau_{r s}$ as a calibrated iceberg trade cost factor. Equivalently, we could reinterpret $\tau_{r s}$ as a calibrated idiosyncratic taste bias [see Balistreri and Rutherford (forthcoming)]. In that case the $\tau_{r s}$ act as quality adjustments that normalize the prices as they enter equation (2). The other introduced trade costs are the ad valorem tariff rates, given by $t_{r s}$.

To determine which firms operate in which market we need to identify the marginal firm (earning zero profits) in each bilateral market, and then relate the marginal firm to the average firm through a well specified productivity distribution. Let $M_{r}$ indicate the mass of region- $r$ firms that are entered (in that they have incurred the sunk cost). These firms are assumed to 
receive their productivity draw from a Pareto distribution with probability density

$$
g(\varphi)=\frac{a}{\varphi}\left(\frac{b}{\varphi}\right)^{a}
$$

and cumulative distribution

$$
G(\varphi)=1-\left(\frac{b}{\varphi}\right)^{a}
$$

where $a$ is the shape parameter and $b$ is the minimum productivity. On each bilateral link there will be a productivity level $\varphi_{r s}^{*}$ at which optimal pricing yields zero profits. A firm drawing $\varphi_{r s}^{*}$ is the marginal firm. Firms drawing a productivity above $\varphi_{r s}^{*}$ will earn positive profits and, therefore, operate, but firms drawing a productivity below $\varphi_{r s}^{*}$ will choose not to operate on the $r$ to $s$ link.

Denoting the fixed cost (in composite input units) associated with operating on the $r$ to $s$ link as $f_{r s}$, the marginal firm earns zero profits at

$$
c_{r} f_{r s}=\frac{r\left(\varphi_{r s}^{*}\right)}{\sigma_{E I T}\left(1+t_{r s}\right)}
$$

where $r\left(\varphi_{r s}^{*}\right)$ is the revenue of the marginal firm which depends on the location of $\varphi_{r s}^{*}$. Following Melitz (2003), however, we simplify the model by defining all of the conditions in terms of the average firm, rather than the marginal firm. To do this we need to relate the productivities and revenues of the average firm relative to the marginal firm in each market. Noting that there will be $N_{r s} / M_{r}=1-G\left(\varphi_{r s}^{*}\right)$ firms operating we can integrate over that portion of the Pareto distribution to find the CES weighted average productivity $\tilde{\varphi}_{r s}$ as a function of the marginal productivity:

$$
\tilde{\varphi}_{r s}=\left[\frac{a}{a+1-\sigma_{E I T}}\right]^{\frac{1}{\sigma_{E I T-1}}} \varphi_{r s}^{*} .
$$

Given the firm-level demand and pricing conditions [equations (3) and (4)] we can establish the 
ratio of the revenues of the average to the marginal firm:

$$
\frac{r\left(\tilde{\varphi}_{r s}\right)}{r\left(\varphi_{r s}^{*}\right)}=\left(\frac{\tilde{\varphi}_{r s}}{\varphi_{r s}^{*}}\right)^{\sigma_{E I T}-1} .
$$

Equations (8) and (9) allow us to represent (7) purely in terms of the average firm. This is the key zero-cutoff-profits condition that determines the number of firms operating in each bilateral market:

$$
c_{r} f_{r s}=\frac{\tilde{p}_{r s} \tilde{q}_{r s}}{\left(1+t_{r s}\right)} \frac{\left(a+1-\sigma_{E I T}\right)}{a \sigma_{E I T}} .
$$

As the optimal markup condition depends on $\tilde{\varphi}_{r s}$ we need to determine this in equilibrium. Given a value of the fraction of operating firms $N_{r s} / M_{h, r}=1-G\left(\varphi_{r s}^{*}\right)$, we can solve for $\varphi_{r s}^{*}$ and substitute it out of (8):

$$
\tilde{\varphi}_{r s}=b\left(\frac{a}{a+1-\sigma_{E I T}}\right)^{1 /\left(\sigma_{E I T}-1\right)}\left(\frac{N_{r s}}{M_{r}}\right)^{-1 / a} .
$$

We now need to determine the measure of the total number of firms, $M_{r}$. This is given by a free-entry condition that balances the sunk entry cost against the expected profits over the lifetime of the firm. Denote the sunk cost for region $r$ in composite input units $f_{r}^{S}$. Consistent with Melitz's steady-state equilibrium, consider that a member of $M_{r}$ has some probability $\delta$ of death in every period. Then in the steady-state equilibrium $\delta M_{r}$ firms must be replaced each period at a total nominal cost of $\delta c_{r} f_{r}^{S} M_{r}$. From the perspective of a given firm (with no discounting or risk aversion) the flow of expected profits would need to cover $\delta c_{r} f_{r}^{S}$. The expected profits in a given market are given by

$$
\tilde{\pi}_{r s}=\frac{\tilde{p}_{r s} \tilde{q}_{r s}}{\sigma_{E I T}\left(1+t_{r s}\right)}-c_{h, r} f_{r s}
$$

and the probability of operating in that market is $N_{r s} / M_{r}$. The free-entry condition, that deter- 
mines $M_{r}$, equates expected profits across all markets with the sunk-cost payments:

$$
c_{r} \delta f_{r}^{S}=\sum_{s} \frac{\tilde{p}_{r s} \tilde{q}_{r s}}{\left(1+t_{r s}\right)} \frac{\left(\sigma_{E I T}-1\right)}{a \sigma_{E I T}} \frac{N_{r s}}{M_{r}},
$$

where we have used the zero-cutoff-profit condition to substitute out the operating fixed costs. With this condition the heterogeneous-firms trade equilibrium is fully specified, but we still need a determination of demand for the composite input. The market clearance condition associated with $c_{r}$ must track the disposition of domestic output into the various sunk, fixed, and variable costs associated with each bilateral market. The market clearance condition is given as

$$
Y_{E I T, r}=\delta f_{r}^{S} M_{r}+\sum_{s} N_{r s}\left(f_{r s}+\frac{\tau_{r s} q_{r s}}{\tilde{\varphi}_{r s}}\right) .
$$

Conditional on regional composite demand and composite-input supply $\left(Q_{E I T, r}\right.$ and $\left.Y_{E I T, r}\right)$, equations (2), (3), (4), (10), (11), (13), and (14) determine the full set of variables associated with the heterogeneous firms trade equilibrium. The corresponding variables are the composite price index $\left(P_{s}\right)$; average-firm prices, quantities, and productivities $\left(\tilde{p}_{r s}, \tilde{q}_{r s}\right.$, and $\left.\tilde{\varphi}_{r s}\right)$; measures of the number of entered and operating firms $\left(M_{r}\right.$, and $\left.N_{r s}\right)$; and the price of the composite input $\left(c_{r}\right)$. Additional details on the heterogeneous-firms theory can be found in Melitz (2003) and Balistreri and Rutherford (forthcoming). 